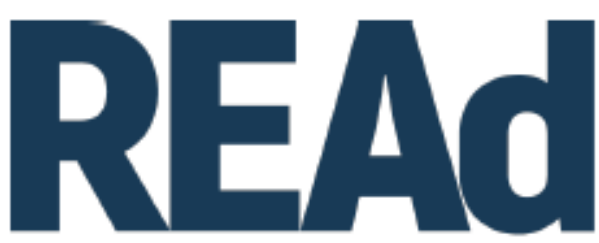

Revista Eletrônica de Administração

\title{
CONSUMO COLABORATIVO: UM ESTUDO BIBLIOMÉTRICO ENTRE 2010 E $2019^{1}$
}

\author{
Verônica Macário de Oliveira ${ }^{2}$ \\ Armindo dos Santos de Sousa Teodósio ${ }^{3}$
}

\section{http://dx.doi.org/10.1590/1413-2311.285.988743}

\section{RESUMO}

Este estudo tem como objetivo analisar o estado da arte sobre consumo colaborativo. Para tanto, foi realizada uma análise bibliométrica sobre o tópico "collaborative consumption" (CC) na base de dados Web of Science, que é em uma das principais bases mundiais de literatura científica revisada por pares. Os resultados demonstram que o tema está em evidente crescimento de interesse. Observou-se que nem sempre o periódico que possui o maior número de artigos publicados é o mais influente em número de citações. A identificação dos periódicos mais influentes corrobora os dados das áreas que mais investigam a temática, a saber: negócios e gestão, representando 43,89\% dos artigos publicados; ciências e estudos ambientais com 31,02\% dos artigos publicados; tecnologia e sistemas de informação, com $25,41 \%$ do total de artigos. Além disso, apenas um autor que está listado entre os que mais produzem sobre a temática emerge entre os mais citados. Os resultados apontam que há diferentes formas de operacionalização do $\mathrm{CC}$ e muita atenção tem sido dada àquelas práticas que possuem intermediários, porém é relevante compreender o impacto que essa intermediação gera tanto no processo quanto no resultado dessa inovação. A análise do fenômeno é baseada em áreas com diferentes abordagens, mas que contribuem para o entendimento das possibilidades e desafios enfrentados pelas redes colaborativas de

\footnotetext{
${ }^{1}$ Recebido em 9/12/2019, aceito em 23/6/2020.

${ }^{2}$ Universidade Federal de Campina Grande - Programa de Pós-Graduação em Administração (PPGA), Campina Grande - PB (Brasil); http://orcid.org/0000-0003-4194-9047; veronicamacario@ gmail.com.

3 PUC Minas - Programa de Pós-Graduação em Administração (PPGA), Belo Horizonte - MG (Brasil); http://orcid.org/0000-0002-7835-5851; armindo.teodosio@gmail.com.
} 
consumo. Assim, apresenta-se uma agenda de pesquisa sobre a gestão de modelos de organização de consumo colaborativo e sua relação com a promoção do consumo sustentável.

Palavras-chave: Consumo Colaborativo. Economia da Partilha. Modelos de Negócios. Sustentabilidade.

\section{COLLABORATIVE CONSUMPTION: A BIBLIOMETRIC STUDY BETWEEN 2010}

\section{AND 2019}

This study aims to analyze state of the art on collaborative consumption. For this purpose, a bibliometric analysis was carried out on the topic "collaborative consumption" (CC) in the Web of Science database, which is in one of the main world databases of peer-reviewed scientific literature. The results show that the topic is clearly growing in interest. It was observed that the journal with the most significant number of published articles is not always the most influential in the number of citations. The identification of the most influential journals corroborates the data of the areas that most investigate the theme, namely: business and management, representing $43.89 \%$ of the published articles; environmental sciences and studies with $31.02 \%$ of published articles; technology and information systems, with $25.41 \%$ of the total articles. Besides, only one author who is listed among those who produce the most on the subject emerges among the most cited. The results indicate that there are different ways of operationalizing the $\mathrm{CC}$, and much attention has been given to those practices that have intermediaries. However, it is relevant to understand the impact that this intermediation generates both in the process and in the result of this innovation. The analysis of the phenomenon is based on areas with different approaches, but which contribute to the understanding of the possibilities and challenges faced by collaborative consumer networks. Thus, a research agenda on the management of collaborative consumption organization models and their relationship with the promotion of sustainable

Keywords: Collaborative Consumption. Sharing Economy. Business Models. Sustainability.

\section{CONSUMO COLABORATIVO: UN ESTUDIO BIBLIOMÉTRICO ENTRE 2010 Y}


Este estudio tiene como objetivo analizar el estado del arte en el consumo colaborativo. Para este propósito, se realizó un análisis bibliométrico sobre el tema "collaborative consumption" (CC) en la base de datos de Web of Science, que es una de las principales bases de datos mundiales de literatura científica revisada por pares. Los resultados muestran que el tema está claramente creciendo en interés. Se observó que la revista con el mayor número de artículos publicados no siempre es la más influyente en el número de citas. La identificación de las revistas más influyentes corrobora los datos de las áreas que más investigan el tema, a saber: negocios y administración, que representan el $43.89 \%$ de los artículos publicados; ciencias ambientales y estudios con $31.02 \%$ de artículos publicados; tecnología y sistemas de información, con el $25,41 \%$ del total de artículos. Además, solo un autor que figura entre los que más producen sobre el tema aparece entre los más citados. Los resultados indican que existen diferentes formas de operacionalizar el CC y se ha prestado mucha atención a aquellas prácticas que tienen intermediarios, sin embargo, es relevante comprender el impacto que genera esta intermediación tanto en el proceso como en el resultado de esta innovación. El análisis del fenómeno se basa en áreas con diferentes enfoques, pero que contribuyen a la comprensión de las posibilidades y desafíos que enfrentan las redes colaborativas de consumidores. Así, se presenta una agenda de investigación sobre la gestión de modelos de organización de consumo colaborativo y su relación con la promoción del consumo sostenible.

Palabras clave: Consumo Colaborativo. Economía Compartida. Modelos de Negocio. Sostenibilidad.

\section{INTRODUÇÃO}

Este estudo tem como objetivo analisar o estado da arte sobre consumo colaborativo (CC). A literatura reconhece o consumo colaborativo como atividades baseadas em ideais de compartilhamento, trocas ou empréstimos de recursos focados na redução da capacidade ociosa, favorecendo o acesso ao invés da posse e a utilização, bem como a utilização de bens até o final de sua vida útil (BOTSMAN; ROGERS, 2011), o que inclui uma ampla variedade de práticas de mercado e outras não mercantis (LAURELL; SANDSTROM, 2017) e tem despertado o interesse de muitos pesquisadores (BOATENG; KOSIBA; OKOE, 2019). Os 
primeiros estudos sobre a temática começaram a ser publicados a partir de 2010, com crescimento expressivo a partir de 2014, conforme pode ser observado em levantamentos realizados neste estudo no banco de dados da Web of Science (WoS). A exceção é um artigo publicado em 1978 (FELSON; SPAETH, 1978), que discute questões relacionadas à economia do espetáculo e do desperdício e o retorno da noção de comunidade, sempre presente nas discussões com relação à dimensão social, reivindicada pela sustentabilidade e pelo bem comum. Nesse sentido, eles definem atos de consumo colaborativo como "aqueles eventos em que uma ou mais pessoas consomem bens ou serviços econômicos no processo de engajar-se em atividades conjuntas com um ou mais outros" (FELSON; SPAETH, 1978, p. 614), de modo que cabe ressaltar que essa definição não é focada especificamente na aquisição e distribuição do recurso, mas em atividades conjuntas envolvendo o consumo (BELK, 2014b).

É importante distinguir que a atividade de compartilhamento não é um fenômeno contemporâneo, estando presente desde as sociedades humanas originais e/ou tradicionais, enquanto o consumo colaborativo e a economia compartilhada são fenômenos nascidos da era da Internet (BELK, 2014b), a partir do uso de plataformas para compartilhar recursos entre as pessoas (BARNES; MATTSSON, 2016). Desde o princípio, o consumo colaborativo é proposto como um passo em potencial em direção a práticas de consumo mais sustentáveis (ROOS; HAHN, 2017), sendo a economia compartilhada vista como um importante bloco de transição para a sustentabilidade (RITTER; SCHANZ, 2019). Apesar do crescente interesse pelo tema, pouco se sabe sobre os determinantes deste comportamento de consumo (ROOS; HAHN, 2017). Um dos livros mais populares publicado sobre o tema tem como título "O que é meu é seu: como o consumo colaborativo vai mudar o mundo", escrito por Botsman \& Rogers (2011). Essa publicação enfatiza que o consumo colaborativo envolve novas formas de fazer negócios e de consumir, que estão sendo potencializadas pelo uso da tecnologia (BELK, 2014b), destacando que consumo colaborativo envolve a coordenação da aquisição e distribuição de um recurso por meio de uma taxa ou outra compensação.

O consumo colaborativo é uma das manifestações mais evidentes da economia compartilhada, com estimativa de movimentação mundial de mais de US\$ 20 bilhões e com um potencial enorme de crescimento nos próximos anos, segundo Malhotra e Van Alstyne (2014). O seu propósito central é a construção de experiências comuns para o acesso e a administração de recursos escassos (ENRIQUE ALONSO, 2017). Alguns veem nesse tipo de consumo a oportunidade de combinar as estratégias de eficiência, suficiência e consistência e 
transformar a forma como os negócios são feitos (HEINRICHS, 2013; RITTER; SCHANZ, 2019; ROOS; HAHN, 2017). Outros o veem como uma possibilidade de gerar acesso ao consumo de produtos e serviços, beneficiando aqueles públicos em situação de vulnerabilidade, exclusão e privação de acesso a recursos (HIRA; REILLY, 2017; RITTER; SCHANZ, 2019). Há ainda aqueles que percebem nesse tipo de consumo a promessa de melhorar as conexões sociais por meio de laços sociais que possibilitem os sentidos de comunidade e de solidariedade, aumentando a coesão social (ACQUIER; DAUDIGEOS; PINKSE, 2017), assim como o bem comum. Em termos econômicos, alguns autores sugerem que o consumo colaborativo traz em si a possibilidade de emancipação política dos indivíduos através de redes organizadas (peer-to-peer), que podem substituir instituições econômicas e políticas convencionais (ACQUIER; DAUDIGEOS; PINKSE, 2017; RITTER; SCHANZ, 2019), provendo novos meios de satisfação de necessidades.

Os motivos elencados para adesão dos consumidores a esse tipo de consumo envolvem tanto aspectos sociais quanto econômicos (BOATENG; KOSIBA; OKOE, 2019; BOTSMAN; ROGERS, 2011; ENRIQUE ALONSO, 2017), dentre os quais destacam-se: 1) a crise financeira que fez com que pessoas buscassem maneiras alternativas de consumir, com foco na relação custo-benefício; 2) os movimentos rápidos e flexíveis de alteração dos estilos de vida moderno; 3) o desenvolvimento tecnológico possibilitando ampla conexão entre pessoas; 4) a ascensão da Internet ajudando a superar barreiras relacionadas aos custos de transação, confiança, principalmente entre estranhos, e reputação, que limitavam as atividades de compartilhamento; 5) e a conveniência dos usuários. Segundo Belk (2014), a sociedade atual vivencia o que ele chama de "economia pós-propriedade", na qual a identidade da pessoa está associada ao que ela compartilha e não mais ao que ela possui, com referência ao aspecto simbólico que o consumo, enquanto atividade cultural, desempenha na vida das pessoas (DOUGLAS; ISHERWOOD, 2009; SLATER, 2001).

Nesse contexto, observa-se que o consumo compartilhado pode ser compreendido e problematizado como fenômeno contemporâneo que adquire formas múltiplas e contraditórias. Os principais aspectos apontados são: 1) uma oportunidade econômica (RITTER; SCHANZ, 2019); 2) uma forma mais sustentável de consumo (ROOS; HAHN, 2017); 3) um caminho para uma economia descentralizada, equitativa e sustentável (HIRA; REILLY, 2017; RIFKIN, 2011); 4) uma criação de mercados não regulamentados (MARTIN, 2016; RIFKIN, 2011); 5) um reforço de um paradigma neoliberal de organização econômica (MARTIN, 2016); e 6) um campo incoerente de inovação (MARTIN, 2016). Esses 
enquadramentos variam de um caminho potencial para a sustentabilidade (HEINRICHS, 2013; ROOS; HAHN, 2017) para uma forma diretamente associada ao neoliberalismo e à cooptação das corporações (MARTIN, 2016). Porém, esses caminhos partilham uma visão comum relacionada à descentralização e alteração de estruturas sociotécnicas e econômicas estabelecidas (MARTIN, 2016; RITTER; SCHANZ, 2019). Daí, emerge o questionamento se aquelas iniciativas de consumo colaborativo, cujas interações entre provedores de produtos/serviços e os consumidores dependem da atuação de atores intermediários (plataformas), podem comprometer a transição dessa prática de consumo para a sustentabilidade.

Como primeiro passo para responder a esse questionamento, este trabalho apresenta uma revisão teórica e estado da arte dos estudos sobre consumo colaborativo através da análise de artigos científicos indexados na Web of Science (WOS) nos últimos 10 anos, por meio de um estudo bibliométrico. Análises bibliométricas têm sido utilizadas para uma melhor análise da produção científica sobre sustentabilidade, na qual se enquadra a pesquisa sobre consumo colaborativo, com grande potencial para a compreensão do estado da arte da pesquisa nesse campo de investigação (SOUZA, 2013). Assim, este estudo indica como o estado de arte está sendo moldado até o presente.

Para tanto, definiu-se algumas características do estado atual da pesquisa sobre o tema, incluindo: o número de artigos publicados ao longo do tempo; as principais revistas que publicaram artigos; a perspectiva analítica utilizada para pesquisa de consumo colaborativo, países e pesquisadores que publicaram os trabalhos; e os principais tópicos que estão sendo relacionados ao tema. Em resumo, este estudo oferece uma visão geral abrangente do panorama atual da pesquisa sobre consumo colaborativo e sua evolução ao longo do tempo, aponta os drivers do campo, sugere vias de investigações a serem exploradas, tendências emergentes e lacunas no tema como principais contribuições do presente artigo.

\section{CONSUMO COLABORATIVO: UMA COMPREENSÃO ABRANGENTE}

$\mathrm{Na}$ literatura acadêmica, o consumo colaborativo está vinculado à emergência da economia compartilhada na década de 1990, em decorrência dos avanços tecnológicos que possibilitaram a redução dos custos das transações online peer-to-peer (BOTSMAN; ROGERS, 2011; HUBER, 2017; MELEO; ROMOLINI; DE MARCO, 2016). Desta forma, 
define-se como "um novo mecanismo econômico e social promissor que começa a equilibrar as necessidades individuais com as das nossas comunidades e as do planeta" (BOTSMAN; ROGERS, 2011, p. 53) e que, conceitualmente, está atrelado a um processo de mudanças econômicas, sociais e ambientais que contribuem para a promoção da sustentabilidade (RITTER; SCHANZ, 2019; ROOS; HAHN, 2017).

Os primeiros artigos publicados sobre a temática abordam a inovação disruptiva do mercado convencional, com o estabelecimento de redes peer-to-peer que possibilitam a organização de comunidades de consumo através de eventos de compartilhamento. Alguns exemplos são o estudo de Albinsson e Perera (2012), abordando práticas alternativas de consumo que não necessariamente envolvem trocas monetárias; a pesquisa de Balnaves (2012) que explora iniciativas de empréstimos peer-to-peer mediados pela internet, fornecendo maneiras alternativas de organizar o relacionamento entre devedor e credor distanciadas das práticas dos bancos tradicionais como agentes de confiança; e o estudo de Huang (2012) que analisa a emergência da cultura de consumo online na China, através de comunidades virtuais.

Em 2013, é publicado um artigo que vincula o consumo colaborativo e a economia compartilhada com potencial de contribuir para os objetivos de sustentabilidade (HEINRICHS, 2013). Essa associação emerge da constatação de que compartilhar significaria $\mathrm{o}$ ato e o processo coordenado de distribuir o que é nosso para o uso de outros e/ou processo de receber algo dos outros para nosso uso (BELK, 2014b; BOTSMAN; ROGERS, 2011). Ou seja, a estratégia do consumo colaborativo seguiria a lógica da redução do consumo material e da ampliação do acesso aos recursos, uma vez que está baseado "em compartilhamento, trocatroca, negociação ou aluguel de acesso a produtos dentro de uma comunidade, em oposição à propriedade pessoal" (HAMARI; SJOKLINT; UKKONEN, 2016a, p. 2052).

Em 2014, o artigo de Belk (2014b), considerando como o mais influente sobre a temática, apresenta exemplos de práticas de compartilhamento, avalia as razões do crescimento atual dessas práticas e suas implicações para as empresas que ainda usam modelos tradicionais de vendas e propriedade. O autor aborda a atividade de pessoa-parapessoa para obter ou partilhar o acesso a bens e serviços através de alguma taxa ou outra compensação não monetária (BELK, 2014b), oferecendo uma alternativa atraente para os consumidores (BENJAAFAR et al., 2019; HAMARI; SJOKLINT; UKKONEN, 2016). Isto é, possui foco no princípio de partilha e daria materialidade ao conceito de economia compartilhada. 
Em 2015, é publicado um estudo que analisa a estrutura sobre os determinantes da escolha de uma opção de compartilhamento de carros e de acomodações em comunidade (Airbnb) (MOEHLMANN, 2015). Os resultados da pesquisa apontam que a satisfação e a probabilidade de escolher uma opção de compartilhamento são explicadas predominantemente pelos determinantes que atendem ao benefício próprio dos usuários. Um aspecto interessante desse estudo é que o impacto ambiental não foi considerado como fator determinante do comportamento dos consumidores investigados, mesmo com alguns autores defendendo que a ideia básica por trás dessas práticas é limitar o nível de propriedade, a fim de reduzir o consumo excessivo e melhorar as conexões sociais (ACQUIER; DAUDIGEOS; PINKSE, 2017; BOTSMAN; ROGERS, 2011), de modo que os consumidores prefeririam pagar pela experiência de obter acesso aos produtos temporariamente, em vez de comprar e possuir bens (BARDHI; ECKHARDT, 2012).

Alguns exemplos do consumo colaborativo demonstram como a qualidade de vida pode ser definida em termos muito menos intensivos materialmente, ao reduzir a pegada de materiais da vida cotidiana por meio de uma utilização mais eficiente e partilha de bens de consumo e espaços (MONT, 2004). Hamari, Sjoklint e Ukkonen (2016) investigaram como as variáveis intrínsecas de prazer e sustentabilidade e as variáveis extrínsecas de benefícios econômicos e reputação influenciam as atitudes e intenções comportamentais dos consumidores em participar do consumo colaborativo. Enfatiza-se que promover o acesso a experiência de consumo é muito mais importante do que a posse material (HAMARI; SJOKLINT; UKKONEN, 2016). Isso auxiliaria na redução dos impactos ambientais e de esgotamento de recursos, além de favorecer questões sociais de inclusão e ampliação do acesso ao consumo. Apesar disso, os autores constataram que a sustentabilidade pode influenciar a atitude dos investigados, mas não tem relação com a sua intenção comportamental no consumo.

É importante investigar a forma como os valores dos consumidores podem influenciar na aceitação, adoção e difusão do consumo colaborativo (ARVIDSSON, 2018; PISCICELLI; COOPER; FISHER, 2015; ROOS; HAHN, 2017). Piscicelli, Cooper e Fisher (2015) utilizaram os modelos psicológicos sociais do comportamento e a teoria da prática social, que vem de perspectivas disciplinares contrastantes e conceituam valores de maneira diferentes, para entender o comportamento pró-ambiental e a sua relação com o consumo colaborativo, de forma a fazer apontamentos de como contribuir para avanços nas pesquisas sobre o tema. 
Outros estudos desenvolvidos depois de 2015 buscaram explorar as formas e modelos de negócios que envolvem as práticas de consumo colaborativo, principalmente nas áreas de transporte, turismo e bens de consumo. Tais práticas se diferem das mais antigas formas de compartilhamento por sua capacidade de facilitar a partilha entre estranhos, principalmente devido aos desenvolvimentos tecnológicos que simplificaram o compartilhamento de dados físicos e não físicos, bem como de bens e serviços através da disponibilidade de vários sistemas de informação na Internet (BELK, 2014b; HAMARI; SJOKLINT; UKKONEN, 2016). Isso impactou a economia tradicional e a forma como são feitos negócios (RITTER; SCHANZ, 2019). Pode-se dizer que a Internet mudou a natureza dos negócios ao conectar vendedores e compradores no espaço virtual de forma quase gratuita e que as novas práticas de negócio colaborativas estão alcançando todos os aspectos da vida econômica (PALMA; NASCIMENTO, 2005; RIFKIN, 2011; BEZERRA, DAVEL, 2017; DELLARMELIN; SEVERO; LAZAROTTO, 2017), o que inclui o consumo colaborativo.

Botsman e Rogers (2011) argumentam que tais plataformas peer-to-peer promovem uma distribuição mais equitativa e sustentável dos recursos, reduzindo tanto os custos de acesso a produtos e serviços quanto a demanda dos consumidores por recursos. Essa natureza da economia compartilhada promoveria a minimização dos custos de transação (economia em escala vertical) e estimularia o consumo (RIFKIN, 2011). Novos modelos organizacionais emergem para as atividades econômicas que se multiplicam a partir dela, gerando uma mudança de mercados para redes, a partir de relações colaborativas entre fornecedores e usuários, nas quais o uso comum de fontes recursos estão desafiando operações de negócios privados (BELK, 2014b; RIFKIN, 2011; SPEZAMIGLIO, GALINA, CALIA, 2016).

Ritter e Schanz (2019) identificaram três modelos de negócios que atuam nesse contexto, em oposição ao modelo tradicional de troca de mercado, com base em critérios específicos de proposição de valor; criação e entrega de valor; e captura de valor, são eles: 1) os modelos baseados em assinatura, que são dominados por relacionamentos duais entre oferta e demanda nos quais, dependendo da orientação da proposição de valor, são fornecidos contratos que garantem uma certa quantidade de produto/serviço; 2) modelos de plataformas baseadas em comissão, que são dominadas por relações entre provedores, intermediários e consumidores com um fluxo de receita vinculado à utilidade e que permitem que seus clientes alternem entre funções de provedor e consumidor, criando e entregando a proposta de valor; e por fim, 3) plataformas ilimitadas que também são dominadas por (pelo menos) relações entre provedores, intermediários e consumidores, porém com os fluxos de receitas sendo 
captados de fontes indiretas, que exigem uma grande massa de usuários regulares e que não pagam, mas criam conteúdo, "cliques" ou dados em troca da mediação do intermediário. Esses modelos podem se correlacionar aos três sistemas definidos por Botsman e Rogers (2011): sistema de serviço de produtos, mercados de redistribuição e estilos de vida colaborativos.

Como pode ser observado, algumas dessas iniciativas possuem dois provedores - um de plataforma e outro de serviço - para atender a um cliente (BENOIT et al., 2017). Ou seja, ao invés de ser um processo peer-to-peer, trata-se de um modelo peer-to-business-to-peer. Benoit et al. (2017) realizaram um levantamento dos diferentes motivos, atividades e recursos relacionados a práticas desses atores no consumo colaborativo, conforme exposto no Quadro 1.

Quadro 1 - Atores, Motivações, Atividades e Recursos no Consumo Colaborativo

\begin{tabular}{|c|c|c|c|}
\hline Ator & Motivações & Atividades & Recursos \\
\hline Cliente & $\begin{array}{c}\text { Econômicas } \\
\text { Sociais } \\
\text { Valor hedônico } \\
\text { Redução de riscos } \\
\text { Benefícios ambientais }\end{array}$ & $\begin{array}{c}\text { Interagir } \\
\text { Fornecer informações } \\
\text { Comportar-se adequadamente }\end{array}$ & $\begin{array}{l}\text { Habilidade técnica para } \\
\text { uso da tecnologia } \\
\text { Recursos financeiros }\end{array}$ \\
\hline $\begin{array}{l}\text { Provedor de } \\
\text { Serviço }\end{array}$ & $\begin{array}{l}\text { Econômicas } \\
\text { Liberdade } \\
\text { empreendedora } \\
\text { Sociais }\end{array}$ & $\begin{array}{c}\text { Acesso a ativos } \\
\text { Contato com clientes } \\
\text { Serviço personalizado }\end{array}$ & $\begin{array}{c}\text { Ativos } \\
\text { Reputação } \\
\text { Confiabilidade }\end{array}$ \\
\hline $\begin{array}{l}\text { Provedor de } \\
\text { Plataforma }\end{array}$ & $\begin{array}{c}\text { Lucros } \\
\text { Inovar e reagir ao } \\
\text { mercado } \\
\text { Construção de redes de } \\
\text { relacionamento }\end{array}$ & $\begin{array}{c}\text { Matchmaking } \\
\text { Apresentar a marca e proposta de valor } \\
\text { Criar confiança e reduzir o risco } \\
\text { Moldar e comunicar normas } \\
\text { Alinhar práticas } \\
\text { Suavizar recursos de acordo com a } \\
\text { demanda }\end{array}$ & $\begin{array}{l}\text { Conhecimento de } \\
\text { mercado } \\
\text { Redes de provedores e } \\
\text { clientes de mesmo nível } \\
\text { Poder de promoção } \\
\text { Relações entre as partes } \\
\quad \text { interessadas }\end{array}$ \\
\hline
\end{tabular}

Fonte: Elaborado pelo autor a partir de Benoit et al. (2017)

Schiel (2015) define a tipologia tridimensional de práticas de compartilhamento atreladas ao consumo da seguinte forma: 1) sistemas de produtos e serviços, que ocorrem quando um consumidor paga pelo benefício do produto e não pelo produto em si; 2) mercados de redistribuição, que ocorrem quando um item usado passa de um lugar onde ele não é mais necessário para onde é; e 3) estilos de vida colaborativos que se baseiam no compartilhamento de recursos em comunidade, tais como dinheiro, habilidades e tempo. Algumas iniciativas caracterizadas como economia compartilhada ou práticas de consumo colaborativo são: eBay, ZipCar, Uber, Airbnb, Freecycle, CouchSurfing e outras iniciativas de coworking (BOTSMAN; ROGERS, 2011; HUBER, 2017). A chamada community supported 
agriculture (CSA) seria outro exemplo de novos modelos de negócios colaborativos que estão gerando impactos sobre o modo de cultivar e distribuir alimentos (RIFKIN, 2011).

Essas práticas podem apresentar respostas para os problemas socioambientais nas áreas que envolvem as práticas cotidianas de consumo, como habitação (CHEN; CHANG, 2018; GUTIERREZ et al., 2017; MELEO; ROMOLINI; DE MARCO, 2016), alimentação (PARKER; UMASHANKAR; SCHLEICHER, 2019), transporte (BOATENG; KOSIBA; OKOE, 2019; LAURELL; SANDSTROM, 2016; STANDING; STANDING; BIERMANN, 2019) e bens de consumo (PARK; ARMSTRONG, 2019), potencializando o uso de recursos e a satisfação de necessidades com base nos preceitos de sustentabilidade. No caso de transporte, especificamente, a posse de carros está deixando de fazer sentido para um número crescente de pessoas, devido ao alto custo de aquisição e manutenção, além da diminuição do interesse de posse como elemento da sua autodefinição, de modo que as empresas automobilísticas veem o aluguel de curto prazo como uma forma de continuarem envolvidas no atendimento das necessidades de transporte (BELK, 2014b; MOUNCE; NELSON, 2019). Isso auxiliaria a reduzir o tráfego, reduzir a poluição, economizar dinheiro e criar eficiências maiores do que as do modelo antigo de motoristas solitários (BELK, 2014b), ao ampliar o acesso e economizar recursos. Ou seja, há uma aproximação conceitual entre os princípios do consumo colaborativo e as dimensões econômica, social, política, cultural e ambiental da sustentabilidade.

Entretanto, apesar dos benefícios sociais e econômicos desse fenômeno, o processo de intermediação que ocorre em algumas das suas formas e modelos de operacionalização têm trazido à tona diversos questionamentos sobre a sua efetividade em atender aos princípios basilares da sustentabilidade, uma vez que o modelo de consumo que era conceitualmente peer-to-peer ( $\mathrm{P} 2 \mathrm{P})$ passa a ser peer-to-business-to-peer (P2B2P). Considera-se que neste contexto há três atores que atuam diretamente no processo: 1) um provedor de plataforma de troca; 2) um cliente que procura acesso a ativos e; 3 ) um provedor de serviços que concede esse acesso (BENOIT et al., 2017).

Além disto, mesmo considerando o crescente aumento do consumo colaborativo, devido em grande parte ao desenvolvimento da Internet, a realidade dos movimentos econômicos e sociais que sustentam essa tendência é muito menos visível, considerando que nem todos os consumidores buscam o consumo colaborativo ou interagem através de plataformas online (HALLEM; BEN ARFI; TEULON, 2019). Assim, os pesquisadores ainda estão no processo de alcançar uma compreensão abrangente do próprio fenômeno, dos fatores 
determinantes e que impedem os consumidores em participar das atividades de consumo colaborativo e da forma de operacionalização dessa prática enquanto modelo de negócio.

Por ser conceitualizado de diferentes formas na literatura, a revisão teórica sobre o tema aponta ambiguidades, principalmente quando confrontadas com as práticas dos indivíduos e das organizações que dizem praticar o consumo colaborativo (BARROS; PATRIOTA, 2017). Portanto, ainda existe uma série de questionamentos e reflexões em torno de sua semântica. Observa-se que algumas questões centrais do consumo colaborativo são apontadas por diversos autores e que necessitam ser analisados - atores envolvidos, formas de operacionalização, relações sociais, impactos causados, entre outros. Desse modo, torna-se importante analisar os direcionamentos que estão sendo adotados na pesquisa sobre a temática e as relações estabelecidas entre abordagens, noções e conceitos centrais, grupos de pesquisa e pesquisadores.

\section{PROCEDIMENTOS METODOLÓGICOS}

A análise bibliométrica refere-se à combinação de diferentes estruturas, ferramentas e métodos para estudar e analisar a literatura e fornecer análises estatísticas que resume as publicações de pesquisa (KESHAVAL; GOWDA, 2008). Este estudo teve como objetivo analisar o estado da arte sobre consumo colaborativo, a partir de uma análise bibliométrica. Foi utilizada a base de dados eletrônica Web of Ciência (WOS) por ser um dos bancos de dados de literatura mais relevantes, cobrindo uma ampla variedade de disciplinas (FALAGAS et al., 2008). A coleção principal do banco de dados de WoS foi a escolhida para a pesquisa, pois reúne periódicos do Science Citation Index Expanded (SCI-EXPANDED); Social Sciences Citation Index (SSCI) e Arts \& Humanities Citation Index (A \& HCI), garantindo que os artigos recuperados sejam de alta qualidade.

Foram analisados os artigos publicados nos últimos 10 (dez) anos que apresentaram a expressão "colaborative consumption" no título, no resumo e/ou nas palavras-chave. Com isso, 303 artigos foram revisados para entender sua evolução teórica e prática da noção de consumo colaborativo e construir uma visão geral sobre o seu o uso nas discussões sobre negócios e sustentabilidade. Verificou-se uma tendência crescente no número de artigos publicados sobre o tema nos últimos 5 anos: 94,4\%, ou seja, 286 artigos identificados na base de dados foram publicados nesse período. 
As estratégias de análise bibliométrica utilizadas foram divididas em duas categorias. Uma categoria fornece informação descritiva sobre a análise estatística relativa ao impacto da investigação sobre a temática e a outra retrata as redes de ligações e cooperação entre diferentes componentes dos artigos, revelando assim as tradições intelectuais dentro de um campo e podem delinear a evolução do campo ao longo do tempo (BATISTIČ; ČERNE; VOGEL, 2017). Os resultados das duas categorias oferecem insights e uma visão abrangente dos esforços de pesquisa e desenvolvimentos na área investigada (CALLON; COURTIAL; PENAN, 1995).

Com base na primeira categoria, foi realizada uma análise de desempenho para descobrir um padrão geral de pesquisa e quantificar o efeito dos artigos científicos sobre consumo colaborativo. A segunda estratégia de análise foi então conduzida para verificar o surgimento e evolução de palavras-chave populares no campo da pesquisa, usando análise de coocorrência de palavras-chave.

Além da planilha eletrônica para tabulação dos dados quantitativos, o principal software bibliométrico utilizado para facilitar os processos de análise de dados foi o VOSviewer (www.vosviewer.com), uma ferramenta especificamente projetada para construir e visualizar mapas bibliométricos através de representação gráfica.

\section{ANÁLISE DOS RESULTADOS}

Uma visão geral abrangente da pesquisa sobre consumo colaborativo é apresentada nesta seção, juntamente com a identificação de tendências e padrões nas seguintes perspectivas: 1) publicações e citações que envolvem autores e áreas de investigação, artigos e periódicos com maiores números de citação, bem como os países e a cooperação regional; 2) surgimento e evolução das palavras-chave relacionadas à temática.

\subsection{PUBLICAÇÕES E CITAÇÕES}

Este estudo identificou a quantidade de 303 artigos publicados de 2010 até 2019, totalizando 669 autores vinculados a 508 instituições, em 54 países e em 215 periódicos. A quantidade de artigos publicados, por ano, é apresentada no Gráfico 1. Silveira, Petrini e Santos (2016) apontaram no seu estudo que no período de 1978 até fevereiro de 2016, consultando diversas bases de dados com base nos critérios de busca "sharing economy" OR 
"collaborative consumption", apenas 44 artigos foram encontrados, escritos por 77 autores e publicados em 35 periódicos.

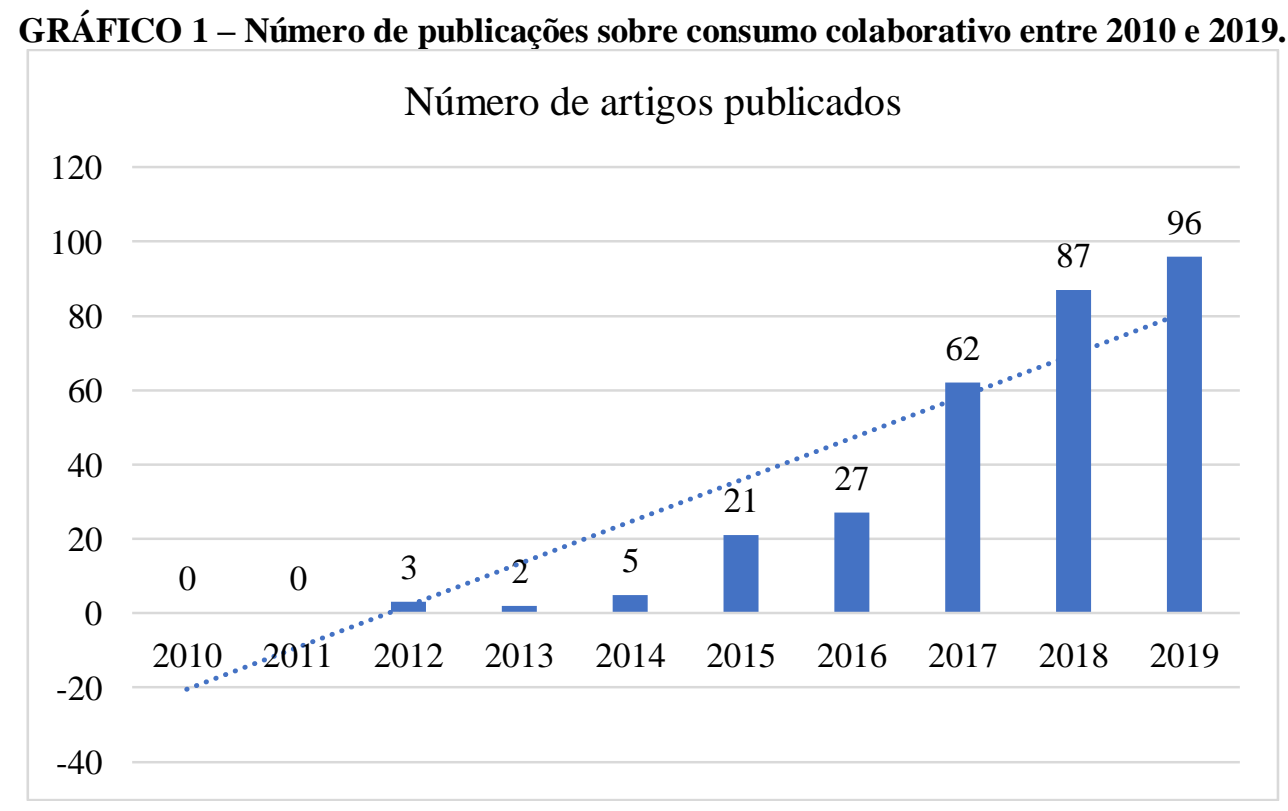

Observa-se uma tendência de crescimento das publicações sobre a temática, considerando a evolução no número de publicações nos últimos anos. Outros estudos bibliométricos realizados sobre a temática "sharing economy" já apontavam o crescimento das pesquisas no campo. Corsini et al. (2019) realizaram uma análise bibliométrica das aplicações das teorias da prática no domínio da pesquisa em sustentabilidade em estudos do consumidor, que apontou para o crescimento futuro das pesquisas nos campos do compartilhamento e da economia circular. Isso porque a economia circular busca dissociar a criação de valor da geração de resíduos e uso de recursos, o que pode provocar uma mudança radical nos sistemas de produção e consumo, a partir da difusão de modelos de negócios circulares (CAMACHO-OTERO; BOKS; PETTERSEN, 2018).

Sobre a produtividade dos autores, onze autores têm 4 ou mais publicações sobre a temática entre as 303 identificadas, o que representa 16,5\% dos casos, conforme se apresenta na Tabela 1. Apesar de serem aqueles que mais produzem sobre a temática, apenas Martin CJ se destaca entre os autores mais citados, conforme apresentado na Tabela 1. Isso demonstra que nem sempre os autores que mais produzem sobre o tema são aqueles que têm mais impacto no campo de investigação.

Tabela 1 - Top 11 dos autores com maior publicação

(c) $\left(\begin{array}{c}() \\ \text { av }\end{array} \operatorname{REAd} \mid\right.$ Porto Alegre - Vol. 26 - N. ${ }^{\circ} 2$ - Maio / Agosto 2020 - p. 300-329. 


\begin{tabular}{|c|c|c|c|}
\hline Ord. & Autores & Registros & $\%$ of 303 \\
\hline 1 & VON HOFFEN M & 6 & $1,98 \%$ \\
\hline 2 & CHASIN F & 5 & $1,65 \%$ \\
\hline 3 & HARTL B & 5 & $1,65 \%$ \\
\hline 4 & HOFMANN E & 5 & $1,65 \%$ \\
\hline 5 & WEBER TA & 5 & $1,65 \%$ \\
\hline 6 & ARMSTRONG CMJ & 4 & $1,32 \%$ \\
\hline 7 & BARNES SJ & 4 & $1,32 \%$ \\
\hline 8 & MARTIN CJ & 4 & $1,32 \%$ \\
\hline 9 & MATZNER M & 4 & $1,32 \%$ \\
\hline 10 & PENZ E & 4 & $1,32 \%$ \\
\hline 11 & RONG K & 4 & $1,32 \%$ \\
\hline \multicolumn{2}{|r|}{ Total } & 50 & $16,50 \%$ \\
\hline
\end{tabular}

Observou-se também que a área de negócios e gestão é a que mais investiga esse tema, representando 43,89\% dos artigos publicados, como foco no impacto que essa nova abordagem pode causar aos setores estabelecidos e às novas oportunidades de negócios decorrentes das práticas de compartilhamento (BELK, 2014b). A segunda área que mais investiga a temática é ciências e estudos ambientais, com 31,02\% dos artigos publicados dado à vinculação do tema com abordagens direcionadas à promoção da sustentabilidade nas práticas de consumo. Em terceiro lugar está a área de tecnologia e sistemas de informação, com $25,41 \%$ do total de artigos publicados no período analisado (Tabela 2), em decorrência da dependência tecnológica que é um dos principais aspectos desse tipo de consumo, caracterizado como consumo de plataforma.

Tabela 2 - Áreas com maior número de investigação

\begin{tabular}{c|l|c|c}
\hline Ord. & \multicolumn{1}{|c|}{ Categorias do Web of Science } & Registros & $\%$ of 303 \\
\hline 1 & Business and Management & 133 & $43,89 \%$ \\
\hline 2 & Environmental Studies and Sciences & 94 & $31,02 \%$ \\
\hline 3 & Computer Science Information Systems & 77 & $25,41 \%$ \\
\hline
\end{tabular}

Fonte: Dados da pesquisa, 2020.

Este estudo também revela o ranking dos artigos mais citados. Foram identificadas 3.337 citações sobre a temática no período analisado. Os dados sobre os artigos mais citados são apresentados na tabela 3 .

Tabela 3 - Artigos mais citados

\begin{tabular}{c|c|c|c|c|c}
\hline Ord. & Título & Autores & Ano & $\begin{array}{c}\mathbf{N}^{\circ} \text { de } \\
\text { citações }\end{array}$ & \% de 3.337 citações \\
\hline 1 & $\begin{array}{l}\text { You are what you can access: Sharing } \\
\text { and collaborative consumption online }\end{array}$ & Belk, Russell & 2014 & 428 & $12,60 \%$ \\
\hline
\end{tabular}




\begin{tabular}{c|l|l|c|c|c}
2 & $\begin{array}{l}\text { The sharing economy: Why people } \\
\text { participate in collaborative consumption }\end{array}$ & $\begin{array}{l}\text { Hamari, Juho; } \\
\text { Sjoklint, Mimmi; } \\
\text { Ukkonen, Antti }\end{array}$ & 2016 & 277 & $8,15 \%$ \\
\hline 3 & $\begin{array}{l}\text { Collaborative } \\
\text { determinants of satisfaction and the } \\
\text { likelihood of using a sharing economy } \\
\text { option again }\end{array}$ & $\begin{array}{l}\text { Moehlmann, } \\
\text { Mareike }\end{array}$ & 2015 & 157 & $4,62 \%$ \\
\hline 4 & $\begin{array}{l}\text { The sharing economy: A pathway to } \\
\text { sustainability or a nightmarish form of } \\
\text { neoliberal capitalism? }\end{array}$ & Martin, Chris J. & 2016 & 153 & $4,50 \%$ \\
\hline 5 & $\begin{array}{l}\text { Transforming homo economicus into } \\
\text { homo ludens: A field experiment on } \\
\text { gamification in a utilitarian peer-to-peer } \\
\text { trading service }\end{array}$ & Hamari, Juho & 2013 & 152 & $4,47 \%$ \\
\hline 6 & $\begin{array}{l}\text { Alternative marketplaces in the 21st } \\
\text { century: Building community through } \\
\text { sharing events }\end{array}$ & $\begin{array}{l}\text { Albinsson, Pia A.; } \\
\text { Perera, B. Yasanthi }\end{array}$ & 2012 & 111 & $3,27 \%$ \\
\hline 7 & $\begin{array}{l}\text { Sharing Economy: A Potential New } \\
\text { Pathway to Sustainability }\end{array}$ & Heinrichs, Harald & 2013 & 103 & $3,03 \%$ \\
\hline 8 & $\begin{array}{l}\text { Sharing Versus Pseudo-Sharing in Web } \\
\text { 2.0 }\end{array}$ & Belk, Russell & 2014 & 102 & $3,00 \%$ \\
\hline 9 & $\begin{array}{l}\text { Sharing economy: A review and agenda } \\
\text { for future research }\end{array}$ & Cheng, Mingming & 2016 & 92 & $2,71 \%$ \\
\hline 10 & $\begin{array}{l}\text { The role of values in collaborative } \\
\text { consumption: insights from a product- } \\
\text { service system for lending and } \\
\text { borrowing in the UK }\end{array}$ & $\begin{array}{l}\text { Piscicelli, Laura; } \\
\text { Cooper, Tim; } \\
\text { Fisher, Tom }\end{array}$ & 2015 & 73 & $2,15 \%$ \\
\hline
\end{tabular}

O artigo mais citado é o de Belk (2014), que compara o compartilhamento e o consumo colaborativo. Ele aponta que essas práticas estão crescendo em popularidade atualmente, apresentando exemplos e razões para esse crescimento e suas implicações para as empresas que ainda usam modelos tradicionais de vendas e propriedade. $\mathrm{O}$ autor busca examinar as diferenças entre compartilhamento e consumo colaborativo. O segundo artigo no ranking é de Hamari et al. (2016), que investiga as motivações das pessoas para participar do CC. Os resultados mostram que essa participação é motivada por vários fatores, como a sustentabilidade, o engajamento na atividade e os ganhos econômicos. Porém, constata-se que a sustentabilidade não está diretamente associada à participação no $\mathrm{CC}$, sugere-se que ela pode ser apenas um fator importante para aquelas pessoas para quem o consumo ecológico é importante.

O terceiro artigo é de Moehlmann e Mareike (2015), que desenvolveram uma estrutura sobre os determinantes da escolha de uma opção de compartilhamento testada com dois estudos quantitativos, um com usuários do serviço de compartilhamento de carros e outro com usuários do mercado de hospedagem comunitária. Os resultados da pesquisa revelaram que a satisfação e a probabilidade de escolher uma opção de compartilhamento são explicadas predominantemente por determinantes que servem ao benefício próprio dos usuários, a saber: 
utilidade, confiança, redução de custos e familiaridade. Esses determinantes foram considerados essenciais em ambos os estudos, enquanto a qualidade do serviço e o pertencimento à comunidade foram identificados apenas entre os usuários do compartilhamento de carro. O impacto ambiental não teve influência sobre nenhuma das variáveis investigadas.

O quarto artigo mais citado é o de Martin (2016), apresentando uma análise do discurso do consumo colaborativo e discutindo as suas contradições que variam de um caminho potencial para a sustentabilidade, para uma forma de "pesadelo do neoliberalismo". O autor enfatiza que se a economia compartilhada seguir esse caminho de "cooptação corporativa", parece improvável que conduza uma transição para a sustentabilidade. O quinto artigo é o de Hamari (2013), que relata os resultados de um experimento de campo que utiliza um serviço de troca peer-to-peer utilitarista a partir da implementação do mecanismo de jogo de crachás, no qual os usuários podem ganhar com uma variedade de tarefas. Os resultados apontam que a gamificação aumentou apenas a atividade de uso no serviço utilitário estudado daqueles usuários que ativamente monitoraram seus próprios crachás e os dos outros.

O sexto artigo é o de Albinsson e Perera (2012), que examinaram práticas de consumo alternativo incluindo o consumo colaborativo, compartilhamento e não-consumo (ou seja, as atividades pós-consumo como upcycling, reutilização, reciclagem, etc.) em mercado não monetários. Os autores enfatizam que há poucas pesquisas sobre esse mercado e que muitos grupos de consumidores agora utilizam esse modelo para organizar eventos de compartilhamento público como forma de aumentar a conscientização sobre vários assuntos, incluindo a sustentabilidade e o consumo excessivo. Destacam que o senso de comunidade é tanto um fator de participação quanto um resultado desses eventos, além de outras razões ideológicas e práticas, e que tais eventos desafiam as noções tradicionais de troca e reciprocidade.

O sétimo artigo é de autoria de Heinrichs (2013), que defende que a economia compartilhada tem o potencial de fornecer um novo caminho para a sustentabilidade, especialmente no campo da produção e consumo de bens e serviços, no qual a sustentabilidade e a igualdade social continuam a ser desafios críticos. O oitavo artigo é o de Belk (2014a), que discute casos aparentes de compartilhamento caracterizados como pseudocompartilhamento de trocas de mercadorias envolvidas em um vocabulário de compartilhamento, pois se distinguem pela presença de motivos de lucro, ausência de sentimentos de comunidade e de expectativas de reciprocidade. 
O nono artigo, cujo autor é Cheng (2016), fornece uma revisão sistemática da literatura acadêmica sobre economia compartilhada e os principais temas subjacentes, revelando que há três áreas com base nos seguintes focos: os modelos de negócio da economia compartilhada e os seus impactos; a natureza da economia compartilhada; e o desenvolvimento da sustentabilidade na economia compartilhada. Além disso, detectaram duas áreas de enfoque no turismo e hospitalidade especificamente, a saber, seus impactos nos destinos e serviços de turismo e para os turistas.

O último artigo é de autoria de Piscicelli, Cooper, e Fisher (2015). Eles investigam como os valores dos consumidores podem influenciar a aceitação, adoção e difusão do consumo colaborativo, utilizando dois quadros teóricos distintos, a partir de métodos mistos, para compreender o comportamento pró-ambiental, modelos psicológicos de comportamentos sociais e teoria da prática social que abordam os valores de maneira diferente. Foi realizado um estudo de caso do Ecomodo, um mercado on-line no Reino Unido no qual as pessoas podem emprestar objetos, espaços e habilidades uns aos outros, além de um estudo quantitativo que identificou e mediu as prioridades de valor entre os usuários do Ecomodo.

Com base na análise das temáticas abordadas nos artigos mais citados, constata-se que a maioria dos estudos estão focados nos seguintes aspectos: 1) na identificação dos modelos de negócios vinculados ao consumo colaborativo a partir de abordagens teóricas que enfatizem as potencialidades estratégicas de tais modelos; 2) aos fatores que podem influenciar o comportamento dos consumidores para engajar-se em tais práticas; 3) e as possibilidades e críticas direcionadas ao discurso de vinculação dessa prática como caminho para alcançar a sustentabilidade nas práticas de consumo. Isto diante da ameaça de cooptação corporativa de grandes corporações que podem atuar como intermediárias para explorar as vantagens desse mercado a partir de princípios neoliberais e da falta de regulamentação do setor.

O número de artigos publicados em cada periódico e o número de citações que cada um deles possui descrevem o impacto dos periódicos mais produtivos sobre consumo colaborativo (Tabela 4). Dos 303 artigos analisados, foram identificados um total de 215 periódicos, dos quais os mais influentes sobre a temática são apresentados na tabela 4.

Tabela 4 - Periódicos mais influentes

\begin{tabular}{c|l|c|c|c|c}
\hline Ord. & Títulos da fonte & Registros & $\begin{array}{c}\text { \%de } \\
\mathbf{3 0 3}\end{array}$ & $\begin{array}{c}\text { Total de } \\
\text { citação }\end{array}$ & $\begin{array}{c}\text { \% de } \\
\mathbf{3 3 3 7}\end{array}$ \\
\hline 1 & Journal of Cleaner Production & 25 & $8,25 \%$ & 285 & $8,54 \%$ \\
\hline
\end{tabular}




\begin{tabular}{c|l|c|c|c|c}
2 & Sustainability & 19 & $6,27 \%$ & 29 & $0,87 \%$ \\
\hline 3 & Technological Forecasting and Social Change & 10 & $3,30 \%$ & 163 & $4,88 \%$ \\
\hline 4 & Lecture Notes in Computer Science & 6 & $1,98 \%$ & 4 & $0,12 \%$ \\
\hline 5 & Journal of Business Research & 5 & $1,65 \%$ & 502 & $15,04 \%$ \\
\hline 6 & Journal of Fashion Marketing and Management & 5 & $1,65 \%$ & 41 & $1,23 \%$ \\
\hline 7 & Electronic Commerce Research and Applications & 4 & $1,32 \%$ & 155 & $4,64 \%$ \\
\hline 8 & $\begin{array}{l}\text { Environmental Innovation and Societal } \\
\text { Transitions }\end{array}$ & 4 & $1,32 \%$ & 62 & $1,86 \%$ \\
\hline 9 & International Journal of Consumer Studies & 4 & $1,32 \%$ & 30 & $0,90 \%$ \\
\hline 10 & Journal of Services Marketing & 4 & $1,32 \%$ & 10 & $0,30 \%$ \\
\hline
\end{tabular}

Observa-se que nem sempre o periódico que possui o maior número de artigos publicados é o mais influente em número de citações. Com base nos dados apresentados, o periódico mais influente é o Journal of Business Research, possui 5 artigos publicados que representam $15,04 \%$ do total de citações sobre a temática, seguido pelos Journal of Cleaner Production, que tem 25 artigos publicados e representa 8,54\% das citações, e o Technological Forecasting and Social Change, com 4,88\% das citações decorrentes de 10 artigos publicados. A identificação dos periódicos mais influentes corrobora os dados das áreas que mais investigam a temática.

A quantidade de publicações por país descreve o impacto daqueles mais produtivos na área de consumo colaborativo (Tabela 5). O estudo compreendeu 54 países. Os Estados Unidos é o país mais influente, com $17,82 \%$ do total de publicações. A Inglaterra é o segundo mais influente com $12,87 \% \%$ da amostra estudada, e a Alemanha aparece em terceiro, com $12,54 \%$ dos artigos. Percebe-se que esses três países juntos publicaram 43,23\% dos artigos relacionados a temática.

Tabela 5 - Países mais influentes

\begin{tabular}{c|l|c|c}
\hline Ord. & Países/Regiões & Registros & \% of 303 \\
\hline 1 & USA & 54 & $17,82 \%$ \\
\hline 2 & England & 39 & $12,87 \%$ \\
\hline 3 & Germany & 38 & $12,54 \%$ \\
\hline 4 & China & 26 & $8,58 \%$ \\
\hline 5 & Australia & 21 & $6,93 \%$ \\
\hline 6 & Finland & 19 & $6,27 \%$ \\
\hline 7 & Spain & 18 & $5,94 \%$ \\
\hline 8 & France & 16 & $5,28 \%$ \\
\hline 9 & Italy & 16 & $5,28 \%$ \\
\hline 10 & Netherlands & 15 & $4,95 \%$ \\
\hline 11 & Sweden & 13 & $4,29 \%$ \\
\hline 12 & Brazil & 10 & $3,63 \%$ \\
\hline 13 & Denmark & 9 & $3,30 \%$ \\
\hline 14 & Switzerland & 8 & $2,97 \%$ \\
\hline 15 & Austria & & \\
\hline & &
\end{tabular}


O desenvolvimento e a cooperação entre países são analisados para identificar as conexões geográficas entre os pesquisadores. Os resultados mostram que a cooperação é encontrada principalmente nos Estados Unidos, Inglaterra e Alemanha, nos quais o número de publicações e citações também são significativamente maiores. Em comparação, o Brasil mostra uma cooperação relativamente menos frequente com outros países em todo o mundo (Figura 1).

Figura 1 - Colaboração entre Países

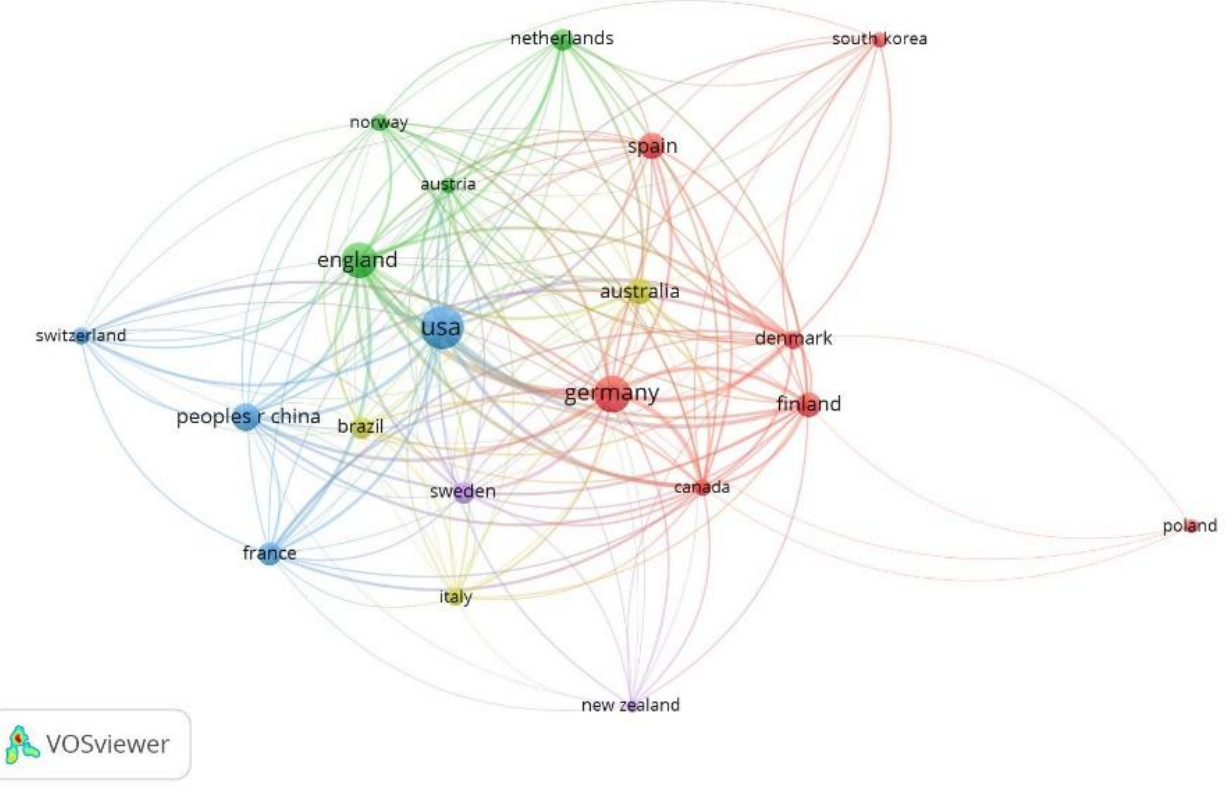

\subsection{SURGIMENTO E EVOLUÇÃO DE PALAVRAS-CHAVE}

As palavras-chave de todos os artigos coletados são extraídas para conduzir a análise da coincidência de palavras-chave tanto em perspectivas gerais quanto longitudinais. Ao coletar palavras-chave de todos os 303 artigos no conjunto de dados, os tópicos que recebem a maior parte da atenção e interesse de pesquisadores na área de pesquisa podem ser identificados. Os resultados de visualização produzidos pelo VOSviewer são apresentados nas Figuras 1 e 2. Para facilitar uma análise eficiente e excluir resultados insignificantes, as palavras-chave que não atenderam à frequência de co-ocorrência de 3 foram excluídas. No geral, 111 palavras-chave atingiram esse limite após a exclusão. A Figura 2 apresenta os resultados da visualização da rede global de co-ocorrência de palavras-chave.

(c) $(1) \Theta$ REAd | Porto Alegre - Vol. 26 - N. ${ }^{\circ} 2$ - Maio / Agosto 2020 - p. 300-329. 
Figura 2 - Rede de Coocorrência de Palavras-Chave.

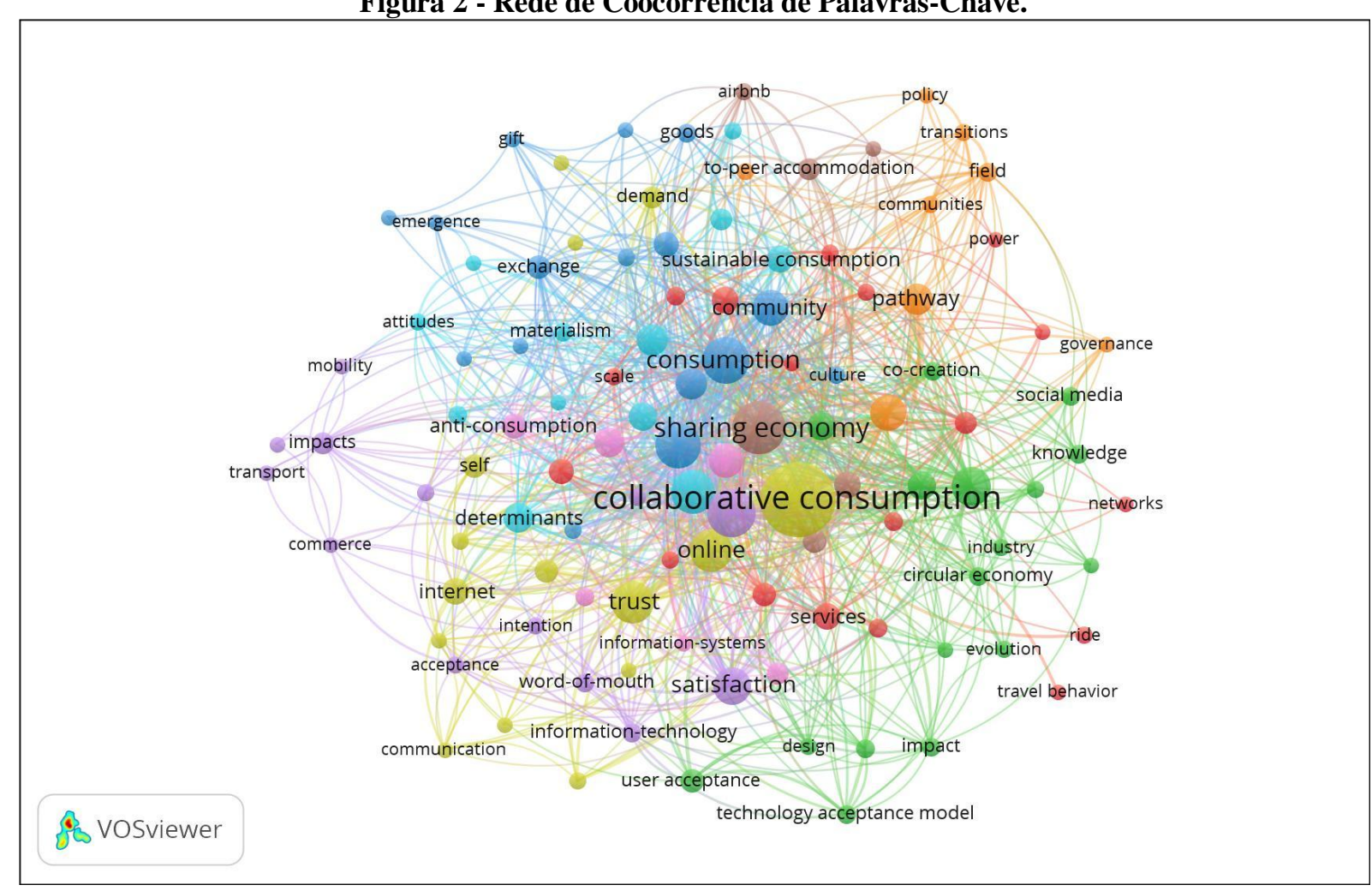

Consumo colaborativo é a palavra-chave com a maior quantidade de ocorrência, aparece 226 vezes, seguida por "economia compartilhada” com 162 aparições. As palavraschave oferecem insights sobre os principais interesses dos pesquisadores e podem ser categorizadas em seis fluxos principais (clusters): 1) comportamento de consumo ("atitudes", "comportamento", "consumidor" e "valores"); 2) formas de operacionalização ("comunidades", "governança", "informação", "inovação social" e "modelo de aceitação tecnológica"); 3) fatores pessoais ("posse", "percepção", "satisfação" e "intenção"); 4) fatores de colaboração ("cocriação", "cooperação", "confiança", "reputação" e "sustentabilidade"); 5) modelos de negócios ("mercado peer-to-peer", "cocriação de valor", "acomodação" e “mobilidade"); e 6) economia circular ("desenvolvimento sustentável”; "peer-to-peer" e “economia compartilhada)." Esses dados sugerem que os pesquisadores estão altamente interessados em entender qual a percepção e atitude dos consumidores quanto a prática do consumo colaborativo, quais são os modelos de negócios colaborativos existentes, suas formas de operacionalização e os impactos que são gerados por esse tipo de consumo, tanto sob uma perspectiva individual quanto coletiva. 
Esses fluxos corroboram o estudo de Lima e Carlos Filho (2019), segundo o qual os principais assuntos encontrados na literatura sobre economia compartilhada, na qual se enquadra o consumo colaborativo, são determinantes, motivações e barreiras comportamentais, impactos da economia compartilhada, aspectos de regulamentação e governança e modelos e estruturas de novos negócios baseados no compartilhamento.

Porém, o referido trabalho não aborda a perspectiva temporal, de modo que o presente artigo inova ao apresentar a evolução do campo em dois períodos distintos. Para investigar a evolução das relações de palavras-chave, o período de 2009-2019 é dividido em duas etapas para outra rodada de análise conjunta, incluindo 2009-2014 e 2015-2019, respectivamente. Os resultados são apresentados nas Figura 3 e 4. Na primeira etapa, quando há menos pesquisas sobre CC, poucas conexões entre palavras-chave podem ser vistas, e elas são bastante dispersas, abordando especificamente sua vinculação com a economia compartilhada, a noção de comunidade e a internet como meio de operacionalização. Como mostram os diagramas, o campo de pesquisa começou a se expandir depois de 2014. Na segunda fase (2015-2019), houve um crescimento significativo no número de palavras-chave e seus relacionamentos e links dos níveis anteriores a 2015.

Figura 3 - Perspectiva longitudinal da rede de co-ocorrência de palavras-chave.

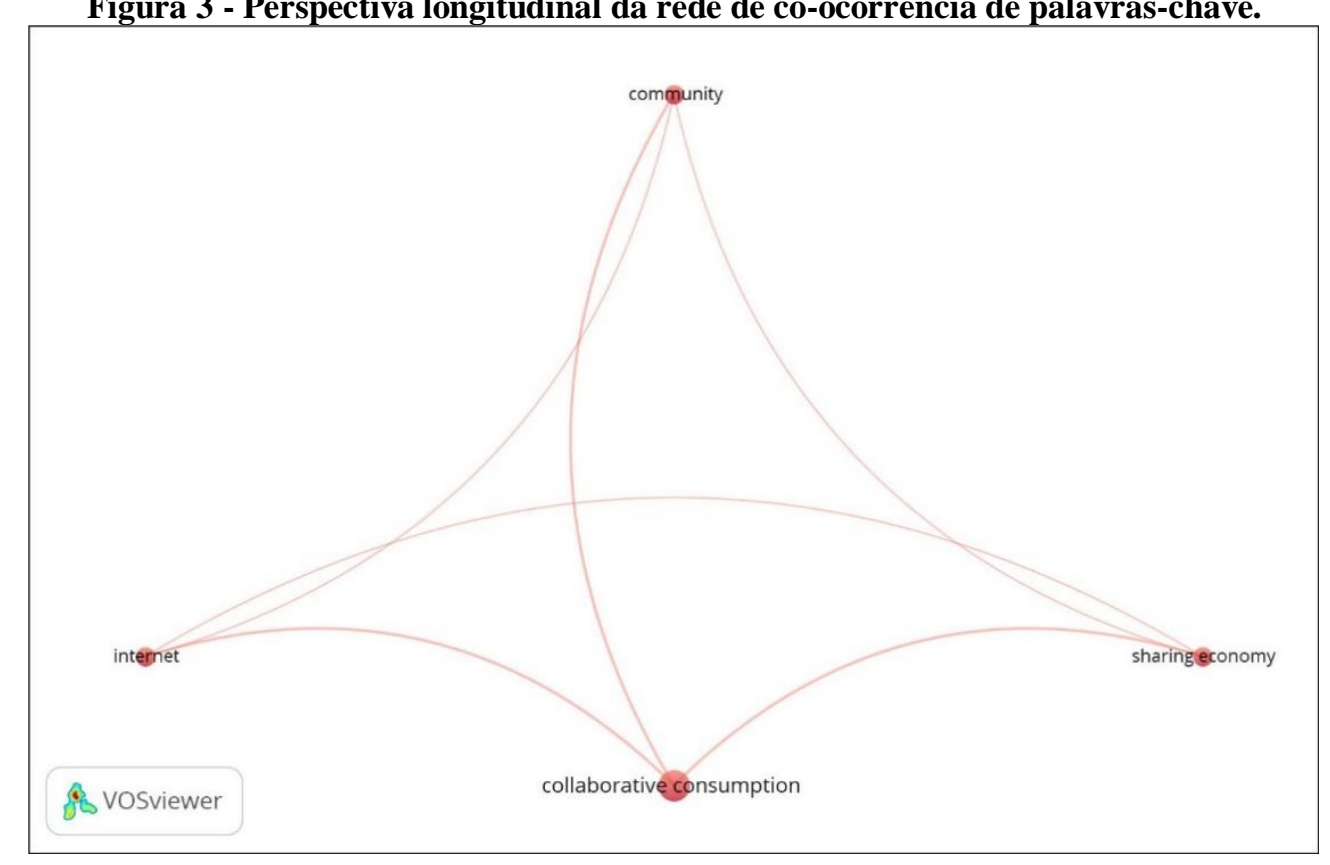

Figura 4 - Perspectiva longitudinal 2015-2019 da rede de co-ocorrência de palavras-chave. 


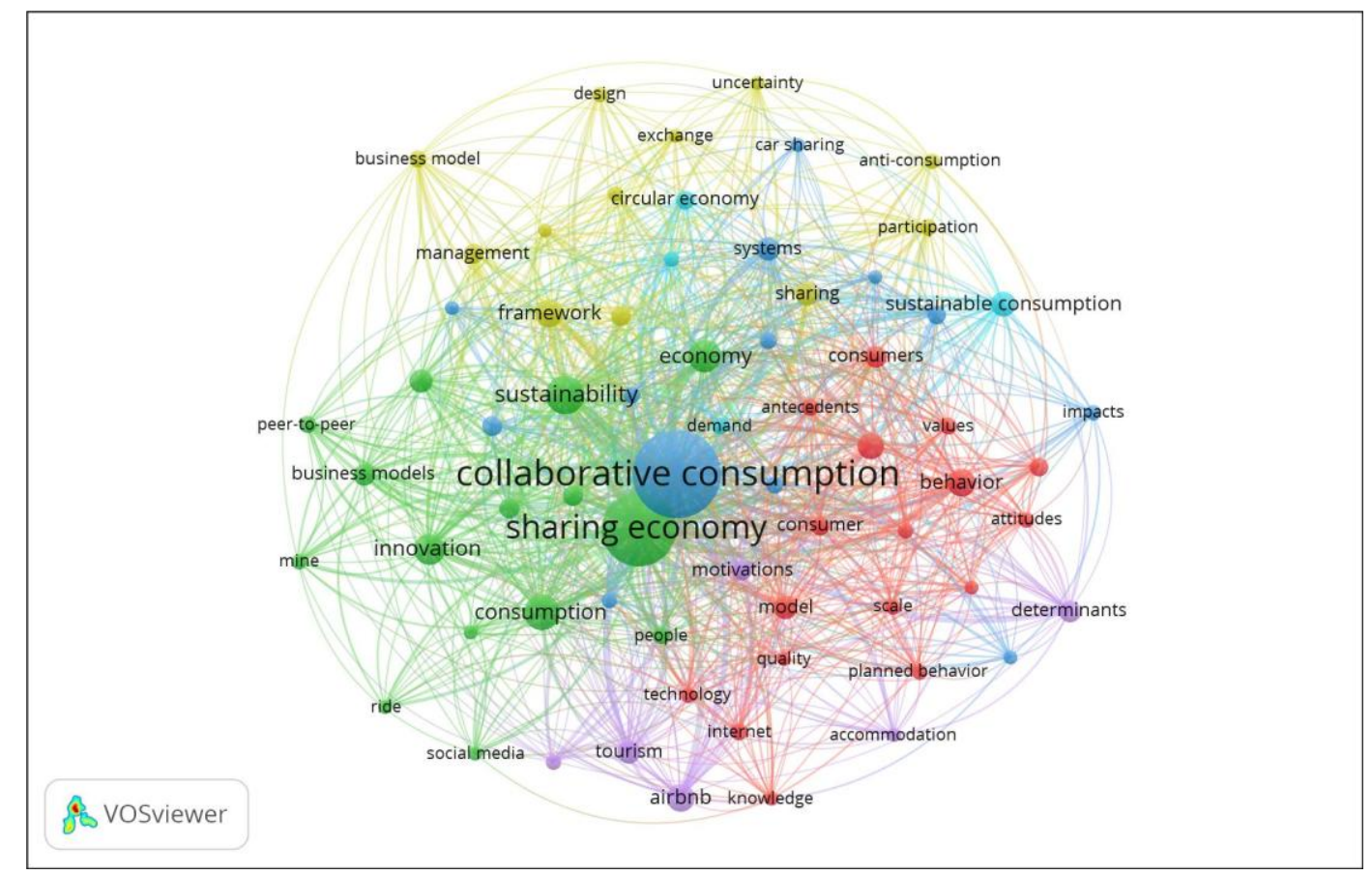

As três principais palavras-chave do estágio 2 são "consumo colaborativo", "economia compartilhada" e "sustentabilidade". Esse segundo estágio das pesquisas sobre consumo colaborativo demonstram a evolução dos estudos sobre a temática. Verificam-se a tendência de sua vinculação com as discussões sobre sustentabilidade das práticas de consumo e desenvolvimento sustentável, além da investigação sobre os determinantes comportamentais para adoção dessa prática, os aspectos técnicos relacionados ao seu contexto enquanto inovação e processo de cocriação de valor e as formas de operacionalização como modelos de negócios.

Com base nestes resultados, foram sumarizados os principais aspectos abordados nas pesquisas sobre a temática, que são apresentados na Figura 6, com seus respectivos direcionamentos de pesquisa.

Quadro 2 - Direcionamentos das pesquisas sobre a temática. 


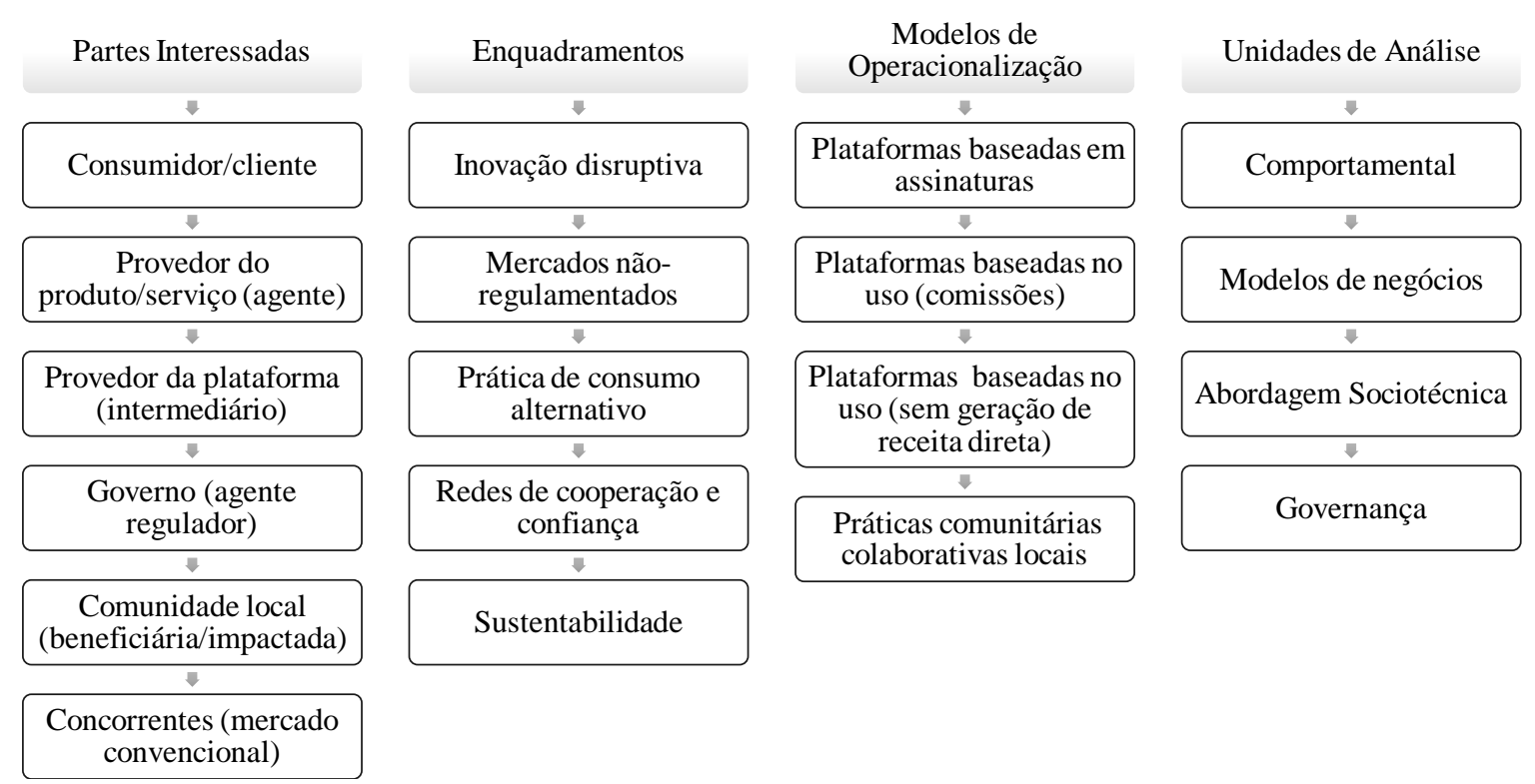

Como pode-se perceber pela análise realizada, são várias as possibilidades e temas e subtemas de investigação que se encontram no campo de estudos voltado ao consumo colaborativo. A compreensão dessa realidade de pesquisa é essencial para o avanço de novas investigações, de forma a ampliar o impacto de novos estudos sobre os debates centrais da área e sobre novas possibilidades de abordagem, delimitação de objetos de estudo e proposição de conceitos e análises sobre esse multifacetado fenômeno chamado consumo colaborativo.

\section{CONSIDERAÇÕES FINAIS}

Este estudo teve como objetivo verificar o status de pesquisas publicadas sobre consumo colaborativo entre os anos de 2009 a 2019, a fim de propor uma agenda para pesquisas futuras. Os resultados ajudam a identificar as principais tendências no campo da pesquisa sobre o tema e indicam que ele está desfrutando de uma ampliação no interesse de pesquisadores que se refletem em um maior número de publicações e citações, favorecendo o seu desenvolvimento como campo de investigação. Três disciplinas principais, ou seja, os negócios e gestão, as ciências ambientais e os sistemas de informação são as que mais contribuem para as pesquisas sobre CC. O estudo bibliométrico indica que o tema ainda está 
em estágio embrionário e envolve questões complexas, que ainda carecem de aprofundamento e debate, bem como novos esforços de pesquisa.

A noção de "colaboração" pode ser uma fonte para o desenvolvimento de ferramentas para analisar redes colaborativas em práticas de consumo que atendam aos preceitos de sustentabilidade, como destaca Heinrichs (2013). Isto depende de valores associados ao desenvolvimento de comunidade, troca e expectativa de reciprocidade (ALBINSSON; PERERA, 2012; BELK, 2014a) e pode abalar os setores estabelecidos (BELK, 2014a, 2014b), que ainda estão orientados para a posse como principal elemento de troca de mercado. Porém, deve-se enfatizar que as atuais motivações identificadas para engajamento e participação no CC ainda estão baseadas em benefícios individuais orientados por princípios de utilidade, redução de custos e conveniência (MARTIN, 2016; MOEHLMANN, 2015).

Esta atividade apresenta diferentes partes interessadas (públicas e privadas). A participação do provedor de plataforma como intermediário é destacada na maioria dos estudos analisados, porque é uma fonte de ampliação das redes de colaboração que podem gerar melhores maneiras de promover o consumo colaborativo (BENOIT et al., 2017). Entretanto, representa também um risco ao potencial de contribuição para a sustentabilidade, devido à possibilidade de cooptação corporativa e associação com a visão estritamente utilitarista dos mercados (MARTIN, 2016). As barreiras potenciais estão vinculadas aos processos de regulamentação, à inconsistência no provimento de produtos/serviços e à necessidade, em alguns casos, de recomendação que interferem na reputação dos participantes (ALBINSSON; PERERA, 2012; STANDING; STANDING; BIERMANN, 2019).

Os fatores considerados como determinantes do consumo colaborativo são tanto de natureza intrínseca quanto extrínseca, mas pouco ainda se sabe sobre eles (ROOS; HAHN, 2017). O fato é que consumo colaborativo tem um sentido prático e econômico para o consumidor, para o meio ambiente, para a comunidade e, também, para empresas suficientemente flexíveis, inovadoras e com visão de futuro (BELK, 2014b). Porém, é importante esclarecer as relações que são estabelecidas a partir das perspectivas das diversas partes interessadas. A análise do fenômeno é baseada em áreas com diferentes abordagens, mas que contribuem para o entendimento das possibilidades e desafios enfrentados pelas redes colaborativas de consumo. Desse modo, o desafio é abordar a temática tanto na perspectiva de processo quanto de resultado. Belk (2014b, p. 1599) enfatiza que "aquecimento global, aumento dos preços de combustíveis e matérias-primas, poluição 
crescente, e outras tendências previsíveis são mais estimulantes para futuras oportunidades de compartilhamento e de consumo colaborativo".

A efetivação desse estudo contribuiu para a identificação de algumas questões-chave que permanecem sem resposta: quais os aspectos essenciais que estão associados a sustentabilidade e a sua relação com o consumo colaborativo? Como as empresas do mercado convencional estão reagindo a essa inovação? Quais os efeitos que a intermediação existente em alguns formas e modelos de consumo colaborativo causam sobre a proposta de sustentabilidade? Em especial, sugere-se como perguntas investigativas de novas agendas de pesquisa: qual é o papel do consumo colaborativo para a sustentabilidade? Que conceito define "colaboração" nas práticas de consumo, a fim de considerá-lo como uma noção conceitual com potencial de contribuição para a sustentabilidade? Quais impactos são gerados a partir das diversas formas de organização enquadradas como práticas de "consumo colaborativo" e seus respectivos modelos de negócio?

A realização de estudos que busquem respostas para tais questionamentos podem gerar impactos sobre a gestão de modelos de organização que busquem promover o consumo sustentável, considerando a necessidade de garantia da existência humana, a diminuição das desigualdades sociais, a manutenção do potencial produtivo da sociedade, e a ampliação do desenvolvimento e das opções de vida previstas nos horizontes que permeiam a sustentabilidade.

\section{REFERÊNCIAS}

ACQUIER, A.; DAUDIGEOS, T.; PINKSE, J. Promises and paradoxes of the sharing economy: An organizing framework. Technological Forecasting and Social Change, v. 125, p. 1-10, dez. 2017.

ALBINSSON, P. A.; PERERA, B. Y. Alternative marketplaces in the 21st century: Building community through sharing events. Journal of Consumer Behaviour, v. 11, n. 4, p. 303315, ago. 2012.

ARVIDSSON, A. Value and virtue in the sharing economy. Sociological Review, v. 66, n. 2, p. 289-301, mar. 2018.

BALNAVES, M. THE AUSTRALIAN FINANCE SECTOR AND SOCIAL MEDIA: TOWARDS A HISTORY OF THE NEW BANKING. Media International Australia, n. 143, p. 132-145, maio 2012.

BARDHI, F.; ECKHARDT, G. M. Access-Based Consumption: The Case of Car Sharing. Journal of Consumer Research, v. 39, n. 4, p. 881-898, dez. 2012. 
BARNES, S. J.; MATTSSON, J. Building tribal communities in the collaborative economy: an innovation framework. Prometheus, v. 34, n. 2, p. 95-113, 2016.

BARROS, A. C. P.; PATRIOTA, K. R. M. P. Consumo colaborativo: perspectivas, olhares e abordagens para um conceito em construção. Signos do Consumo, v. 9, n. 2, p. 4-15, 2017.

BATISTIČ, S.; ČERNE, M.; VOGEL, B. Just how multi-level is leadership research? A document co-citation analysis 1980-2013 on leadership constructs and outcomes. The Leadership Quarterly, v. 28, n. 1, p. 86-103, 2017.

BELK, R. Sharing Versus Pseudo-Sharing in Web 2.0. Anthropologist, v. 18, n. 1, p. 7-23, jul. 2014a.

BELK, R. You are what you can access: Sharing and collaborative consumption online. Journal of Business Research, v. 67, n. 8, p. 1595-1600, ago. 2014 b.

BENJAAFAR, S. et al. Peer-to-Peer Product Sharing: Implications for Ownership, Usage, and Social Welfare in the Sharing Economy. Management Science, v. 65, n. 2, p. 477-493, fev. 2019.

BENOIT, S. et al. A triadic framework for collaborative consumption (CC): Motives, activities and resources \& capabilities of actors. Journal of Business Research, v. 79, p. 219-227, out. 2017.

BOATENG, H.; KOSIBA, J. P. B.; OKOE, A. F. Determinants of consumers' participation in the sharing economy A social exchange perspective within an emerging economy context.

International Journal of Contemporary Hospitality Management, v. 31, n. 2, p. 718-733, 11 fev. 2019.

BOTSMAN, R.; ROGERS, R. O que é meu é seu: como o consumo colaborativo vai mudar o nosso mundo. [s.l.] Bookman Editora, 2011.

CALLON, M.; COURTIAL, J.-P.; PENAN, H. Cienciometría: la medición de la actividad científica: de la bibliometría a la vigilancia tecnológica. [s.l.] Trea, 1995.

CAMACHO-OTERO, J.; BOKS, C.; PETTERSEN, I. N. Consumption in the Circular Economy: A Literature Review. Sustainability, v. 10, n. 8, p. 2758, ago. 2018.

CHEN, C.-C.; CHANG, Y.-C. What drives purchase intention on Airbnb? Perspectives of consumer reviews, information quality, and media richness. Telematics and Informatics, v. 35 , n. 5, p. 1512-1523, ago. 2018.

CHENG, M. Sharing economy: A review and agenda for future research. International Journal of Hospitality Management, v. 57, p. 60-70, ago. 2016.

CORSINI, F. et al. The Advent of Practice Theories in Research on Sustainable Consumption: Past, Current and Future Directions of the Field. Sustainability, v. 11, n. 2, p. 341, 2 jan. 2019.

DOUGLAS, M.; ISHERWOOD, B. O mundo dos bens: para uma antropologia do consumo. 2. reimpr. Rio de Janeiro: UFRJ, 2009. 
ENRIQUE ALONSO, L. Collaborative Consumption: Reasons for a Debate. Revista Espanola De Sociologia, v. 26, n. 1, p. 87-95, jan. 2017.

FALAGAS, M. E. et al. Comparison of PubMed, Scopus, web of science, and Google scholar: strengths and weaknesses. The FASEB journal, v. 22, n. 2, p. 338-342, 2008.

FELSON, M.; SPAETH, J. L. Community structure and collaborative consumption: A routine activity approach. American behavioral scientist, v. 21, n. 4, p. 614-624, 1978.

GUTIERREZ, J. et al. The eruption of Airbnb in tourist cities: Comparing spatial patterns of hotels and peer-to-peer accommodation in Barcelona. Tourism Management, v. 62, p. 278 291, out. 2017.

HALLEM, Y.; BEN ARFI, W.; TEULON, F. Exploring consumer attitudes to online collaborative consumption: A typology of collaborative consumer profiles. Canadian Journal of Administrative Sciences-Revue Canadienne Des Sciences De L Administration, 2019.

HAMARI, J. Transforming homo economicus into homo ludens: A field experiment on gamification in a utilitarian peer-to-peer trading service. Electronic Commerce Research and Applications, v. 12, n. 4, p. 236-245, ago. 2013.

HAMARI, J.; SJOKLINT, M.; UKKONEN, A. The sharing economy: Why people participate in collaborative consumption. Journal of the Association for Information Science and Technology, v. 67, n. 9, p. 2047-2059, set. 2016.

HEINRICHS, H. Sharing Economy: A Potential New Pathway to Sustainability. GaiaEcological Perspectives for Science and Society, v. 22, n. 4, p. 228-231, 2013.

HIRA, A.; REILLY, K. The emergence of the sharing economy: Implications for development. Journal of Developing Societies, v. 33, n. 2, p. 175-190, 2017.

HUANG, X. Lifestyles in virtual communities: collaborative consumption and interaction. Chinese Journal of Communication, v. 5, n. 1, p. 109-127, 2012.

HUBER, A. Theorising the dynamics of collaborative consumption practices: A comparison of peer-to-peer accommodation and cohousing. Environmental Innovation and Societal Transitions, v. 23, p. 53-69, jun. 2017.

KESHAVAL, G.; GOWDA, M. ACM transaction on information systems (1989-2006): A bibliometric study. Information Studies, v. 14, n. 4, p. 223-234, 2008.

LAURELL, C.; SANDSTROM, C. ANALYSING UBER IN SOCIAL MEDIA DISRUPTIVE TECHNOLOGY OR INSTITUTIONAL DISRUPTION? International Journal of Innovation Management, v. 20, n. 5, p. UNSP 1640013, jun. 2016.

LAURELL, C.; SANDSTROM, C. The sharing economy in social media: Analyzing tensions between market and non-market logics. Technological Forecasting and Social Change, $v$. 125, p. 58-65, dez. 2017. 
LIMA, S.; CARLOS FILHO, F. DE A. Bibliometric analysis of scientific production on sharing economy. Rege-Revista De Gestao, v. 26, n. 3, p. 237-255, 2019.

MALHOTRA, A.; VAN ALSTYNE, M. The Dark Side of the Sharing Economy ... and How to Lighten It. Communications of the Acm, v. 57, n. 11, p. 24-27, nov. 2014.

MARTIN, C. J. The sharing economy: A pathway to sustainability or a nightmarish form of neoliberal capitalism? Ecological Economics, v. 121, p. 149-159, jan. 2016.

MELEO, L.; ROMOLINI, A.; DE MARCO, M. The Sharing Economy Revolution and Peerto-peer Online Platforms. The Case of Airbnb. In: BORANGIU, T.; DRAGOICEA, M.; NOVOA, H. (Eds.). . Exploring Services Science (iess 2016). Berlin: Springer-Verlag Berlin, 2016. v. 247p. 561-570.

MOEHLMANN, M. Collaborative consumption: determinants of satisfaction and the likelihood of using a sharing economy option again. Journal of Consumer Behaviour, v. 14, n. 3, p. 193-207, jun. 2015.

MONT, O. Institutionalisation of sustainable consumption patterns based on shared use. Ecological Economics, v. 50, n. 1-2, p. 135-153, 1 set. 2004.

MOUNCE, R.; NELSON, J. D. On the potential for one-way electric vehicle car-sharing in future mobility systems. Transportation Research Part a-Policy and Practice, v. 120, p. 17-30, fev. 2019.

PARK, H.; ARMSTRONG, C. M. J. Will "no-ownership" work for apparel?: Implications for apparel retailers. Journal of Retailing and Consumer Services, v. 47, p. 66-73, mar. 2019.

PARKER, J. R.; UMASHANKAR, N.; SCHLEICHER, M. G. How and Why the Collaborative Consumption of Food Leads to Overpurchasing, Overconsumption, and Waste. Journal of Public Policy \& Marketing, v. 38, n. 2, p. 154-171, abr. 2019.

PISCICELLI, L.; COOPER, T.; FISHER, T. The role of values in collaborative consumption: insights from a product-service system for lending and borrowing in the UK. JOURNAL OF CLEANER PRODUCTION, v. 97, n. SI, p. 21-29, 15 jun. 2015.

RIFKIN, J. The third industrial revolution: how lateral power is transforming energy, the economy, and the world. [s.1.] Macmillan, 2011.

RITTER, M.; SCHANZ, H. The sharing economy: A comprehensive business model framework. Journal of Cleaner Production, v. 213, p. 320-331, 10 mar. 2019.

ROOS, D.; HAHN, R. Does shared consumption affect consumers' values, attitudes, and norms? A panel study. Journal of Business Research, v. 77, p. 113-123, ago. 2017.

SILVEIRA, L. M.; PETRINI, M.; SANTOS, A. C. M. Z. Economia compartilhada e consumo colaborativo: o que estamos pesquisando? REGE-Revista de Gestão, v. 23, n. 4, p. 298-305, 2016.

SLATER, D. Cultura do consumo \& modernidade-Exame. [s.1.] NBL Editora, 2001. 
STANDING, C.; STANDING, S.; BIERMANN, S. The implications of the sharing economy for transport. Transport Reviews, v. 39, n. 2, p. 226-242, 4 mar. 2019.

(c) $\underset{\text { (1) }(9)}{\text { ar ne }}$ REAd | Porto Alegre - Vol. 26 - N. ${ }^{\circ} 2$ - Maio / Agosto 2020 - p. 300-329. 